\title{
Janus and the Great Men
}

\author{
Yves Menu ${ }^{1}$ (D)
}

Received: 3 October 2017 / Accepted: 11 October 2017 /Published online: 13 November 2017

(C) European Society of Radiology 2017

Whether January was named after Janus or Juno, we don't know; however, having two faces, one for the past, one for the future, Janus perfectly stands for beginnings and passages, as legacy and memory help to imagine the new and the possible. This fits with January, as well as with a handover.

It is an incredible honour, as well as a challenge, to take over the position of Editor-in-Chief of European Radiology from Prof. Dr. Dr. h.c. Maximilian F. Reiser, who has elevated the scientific level of the Journal, encouraging authors and reviewers to delve deep into the fundamentals of research while still keeping it accessible. He introduced a systematic check of statistical data before publication. He himself received this venerated heritage from Prof. Dr. Dr. h.c. Josef Lissner, the founder of the journal in 1991, Prof. Dr. Albert L. Baert, who organised a professional and modern workflow, and Prof. Dr. Adrian K. Dixon, who set up most of the quality processes that we still use today and who built a very personalised relationship with authors and reviewers. These great men have been the actors in a wonderful success story, each with their own personality and all with utmost dedication.

Ignoranti quem portum petat, nullus suus ventus est, said Seneca (If one does not know to which port one is sailing, no wind is favourable). Our port is scientific recognition, and four winds will guide us: Timeliness, Transparency, Ethics and Professionalism.

Timeliness is a major comment or complaint about publication. European Radiology is no exception here. Fortunately, there are several ways to streamline and speed up the process.

Yves Menu

yves.menu@european-radiology.org

1 Department of Radiology, Saint Antoine Hospital and University Pierre and Marie Curie, 184 rue du Faubourg Saint-Antoine, 75012 Paris, France
The first one is to shorten the mean time from submission to first decision as much as possible. Obviously, we need time for peer reviews, some manuscripts might be controversial, requiring more than two opinions, or so focused that it is difficult to even find relevant reviewers. However, my commitment will be that the average delay between submission and first decision remains below 30 days for $95 \%$ of manuscripts.

A second problem is the total turn-around, including revision(s). Having a high percentage of manuscripts that require two, three and even four major revisions is an abnormal situation. The rule should be one revision, sometimes two, returned by the authors within 45 days, followed by final editing. One reason for keeping the number of revisions high is the amount of changes that are required from the very beginning, both in the construction of the manuscript and in the presentation of scientific data. Reviewers should be able to concentrate their attention on the latter, and not lose time with the former. For this reason, a higher number of manuscripts will be rejected with an invitation, and even encouragement, to resubmit. My experience is that manuscripts resubmitted after a rejection show a lot of improvement, and are commonly accepted after a single revision, at least if the scientific message is considered valid by the reviewer. Don't be discouraged by a 'reject-resubmit' decision! At the end of the day, it might be a good outcome! We will publish revised instructions to authors shortly, hopefully helping them to improve manuscript preparation.

Another initiative will be to propose and increase the role of Fast Tracks. For some manuscripts, the scientific message is important and original. Having it reviewed and released very quickly is instrumental. Upon request in a specific cover letter, the Editors will organise such a rapid review, if they agree that the manuscript deserves it.

Transparency is an important requirement. European Radiology will publish approximately $20 \%$ out of the 2,300 expected submissions in 2017. The difficult task is to reject 
more than 1,800 . I have never met an editor who likes rejection. Letters containing negative decisions are painful for both authors and editors. However, a rejection does not mean the end of the story, as such a manuscript will commonly be submitted to another journal. Hopefully, opinions received from reviewers will greatly help to remodel the manuscript.

Authors often recognise that reviews provided by European Radiology are useful and independent. However, sometimes it happens that the authors of a rejected manuscript feel that the reviewers have misunderstood their message. My intention is to develop a procedure in order to allow an anonymised communication between authors and reviewers. This will not change the editor's decision; however, these exchanges might be profitable for both sides. A rejected manuscript might also be considered for potential resubmission.

Authors will soon be asked online, whatever the decision, whether they are satisfied with the timeline and with the quality of reviews. The results of this survey will be publicly released.

Ethics is a key step for building trust, and we pay much attention to it. Any conflicts of interest that authors, reviewers or even editors have must be disclosed. Intellectual property for authors and reviewers should be guaranteed. We do not want ghost or honorary authorships. There should be no plagiarism, no duplication of publication. Multiple publications with the same cohort should be announced and clarified by authors. We now have tools at our disposal that help us detect these various problematic and potentially unethical situations, which fortunately are the exception in our environment.

Professionalism is a necessity, and is a major concern for all the stakeholders of the journal.

The joint venture between the European Society of Radiology (ESR), the editor and Springer Nature, our publisher, is a win-win situation in this regard, combining complementary expertise and capabilities.

When I started working with the editorial office, seeing the enormous number of duties and how they were managed, I thought that a large body of staff was involved. I found out that there were only a dedicated few; they work as if they were many! It was a pleasure to meet this group and I am delighted to have the opportunity to share my project with this incredible team.

The role of the deputy editors needs to be highlighted. They expertly manage a large number of manuscripts from submission to final decision. They are instrumental, and receive a great amount of help from the members of the Editorial Board, who allocate much of their time to our journal, for the sole benefit of science.
Without the commitment of reviewers, there would be no valuable scientific journal. I admire those who accept invitations to review the manuscripts. It is time-consuming, while our institutions constantly increase the pressure on productivity. It requires a high level of scientific knowledge, all the while remaining anonymous. We will propose some templates and recommendations to make their task easier.

European Radiology is not an island. It belongs to the ESR and has a family of journals, Insights Into Imaging, and the newly born European Radiology Experimental, with Prof. Dr. Luis Martí-Bonmatí and Prof. Dr. Francesco Sardanelli as their respective Editors-in-Chief. Our three journals intend to work in close relationship in order to offer a complete spectrum of publications for our community.

European Radiology is strongly and constantly supported by the ESR. Although this could be considered invidious for many others who contribute so much, I would like to thank Prof. Dr. Paul M. Parizel, Chairman of the Board of Directors, Prof. Dr. Regina G. H. Beets-Tan, Chair of the Publications Committee and Peter Baierl, Executive Director of the ESR, who create the ideal environment for the development of the journal.

It is my pleasure to wish all of you a very happy new year, obviously very productive in the field of publication!

\section{Compliance with ethical standards}

Guarantor The scientific guarantor of this publication is Yves Menu

Conflict of interest The authors of this manuscript declare no relationships with any companies whose products or services may be related to the subject matter of the article.

Funding The authors state that this work has not received any funding.

Statistics and biometry No complex statistical methods were necessary for this paper.

Informed consent This is an opinion, not a study.

Ethical approval Approval from the institutional animal care committee was not required because this is an opinion, not a study.

Study subjects or cohorts overlap This is an opinion, not a study.

Methodology This is an opinion, not a study. 